\title{
New Delhi Metallo-beta-lactamase-producing Enterobacter Cloacae - A Rare Multidrug Resistance Strain in a Caucasian Woman
}

\author{
Suman Siddamreddy ${ }^{1}$, Sreenath Meegada ${ }^{2}$, Vasuki Dandu ${ }^{3}$, Vijayadershan Muppidi ${ }^{4}$, Ramya Bachu ${ }^{5}$ \\ 1. Internal Medicine, Baptist Health Medical Center, North Little Rock, USA 2. Internal Medicine, The University of \\ Texas Health Science Center/Christus Good Shepherd Medical Center, Longview, USA 3. Neurology, Baptist Health \\ Medical Center, Little Rock, USA 4. Internal Medicine, Indiana University Health, Indianapolis, USA 5. Internal \\ Medicine, Baptist Health-University of Arkansas for Medical Sciences, North Little Rock, USA
}

Corresponding author: Suman Siddamreddy, siddam.suman@gmail.com

\begin{abstract}
New Delhi metallo-beta-lactamase (NDM-1) is a novel metallo-beta-lactamase (MBL) gene carried by some Enterobacteriaceae that induces resistance to most of the antibiotics. First described in a Swedish patient hospitalized in India with an infection due to Klebsiella pneumoniae. NDM-1 makes bacteria resistant to a broad range of beta-lactam antibiotics. These include the antibiotics of the carbapenem family, which are a mainstay for the treatment of antibiotic-resistant bacterial infections. Most of these carbapenem resistant Enterobacteriaceae (CRE) are increasingly recognized in hospital settings and post-acute care settings like long-term acute care settings. Percentage of CRE infections is increasing in the United States of America, and invasive infections with CRE carry high mortality rates and limited treatment options. We here present a rare case of elderly Caucasian woman with CRE cellulitis of both legs with no travel history.
\end{abstract}

Categories: Dermatology, Internal Medicine, Infectious Disease

Keywords: enterobacteriaceae, ndm-1, superbug, new delhi metallo beta lactamase, multi drug resistant strain

\section{Introduction}

Enterobacteriaceae with New Delhi metallo-beta-lactamase (NDM-1) gene are occasionally reported in the United States of America (USA) from time to time. Most of the early cases in the USA were in those patients who received prior medical care in countries like India, Pakistan, and Middle East [1]. But patients with these strains who had not traveled outside the USA started to emerge from 2012 [2]. Surveillance of these strains is really important for early detection of these patients for appropriate treatment and also to prevent further spread. We report a case of 75 -year-old Caucasian female who has chronic venous ulcers infected with NDM-1 Enterobacter. The patient was treated with Tigecycline, improved and was discharged home in stable condition.

Received 02/27/2020

Review began 02/29/2020 Review ended 02/29/2020 Published 03/04/2020

๑) Copyright 2020

Siddamreddy et al. This is an open access article distributed under the terms of the Creative Commons Attribution License CC-BY 4.0., which permits unrestricted use, distribution, and reproduction in any medium, provided the original author and source are credited.

\section{Case Presentation}

A 75-year-old Caucasian female was admitted to the hospital with bilateral cellulitis and non-healing wounds of both lower extremities. Past history was significant for chronic kidney disease, coronary artery disease, diabetes, bio-prosthetic aortic valve replacement and smoking dependence. She had these wounds for two months and used Silvadene and Vaseline to treat them at home. She also used some unknown oral antibiotics initially and they got better. She has not travelled outside the United States. Later she developed fever, chills with worsening pain and redness of the legs, and was admitted to the hospital. On exam, she had large $16 \times 6.5 \times 1 \mathrm{~cm}$ ulcer in left posterior leg and small $0.5 \times 0.5 \times 1 \mathrm{~cm}$ ulcer in right anterior lower leg, with diffuse erythema and warmth of both legs. Peripheral pulses were palpable. Remaining exam was unremarkable. Admission labs were significant for elevated white blood cell count of $11 \mathrm{k} / \mathrm{cmm}$ (Reference range: $5-10 \mathrm{k} / \mathrm{cmm}$ ), and creatinine of $1.06 \mathrm{mg} / \mathrm{dl}$ (Reference range: $0.5-1.2 \mathrm{mg} / \mathrm{dl}$ ). Wound care specialist was consulted and the left leg wound was debrided at bedside and wound cultures were sent out.

The patient was empirically started on intravenous (IV) Vancomycin and Piperacillin/Tazobactam. Tissue culture grew Enterobacter cloacae (Table 1). 


\section{Cureus}

Specimen: Tissue Leg, Left

Gram stain result: Gram negative rod.

Culture: Light Growth Enterobacter Cloacae.

Positive Carbapenemase

SUSCEPTIBILITY

$\begin{array}{lc}\text { Amikacin } & <=8 \text { Sensitive } \\ \text { Aztreonam } & <=4 \text { Sensitive } \\ \text { Cefazolin } & >=64 \text { Resistant } \\ \text { Cefepime } & >16 \text { Resistant } \\ \text { Ceftazidime } & >=64 \text { Resistant } \\ \text { Ceftriaxone } & >=64 \text { Resistant } \\ \text { Ceftazidime/Avibactam } & >32 \text { Resistant } \\ \text { Ciprofloxacin } & 0.5 \text { Intermediate } \\ \text { Gentamycin } & <=1 \text { Sensitive } \\ \text { Levofloxacin } & 1 \text { intermediate } \\ \text { Meropenem } & 8 \text { Resistant } \\ \text { Piperacillin/Tazobactam } & >=320 \text { Resistant } \\ \text { Tigecycline } & >64 \text { Resistant } \\ \text { Tobramycin } & <=1 \text { Sensitive } \\ \text { Trimethoprim/Sulfamethoxazole } & <=\text { Sensitive }\end{array}$

TABLE 1: Wound culture and sensitivities

Sensitivities revealed that Enterobacter cloacae was resistant to extended spectrum cephalosporins, an elevated carbapenem MIC and having NDM-1 gene (Table 2).

Component

Specimen description $=$ Tissue

Klebsiella Pneumoniae Carbapenemase (KPC)--Not detected

New Delhi metallo-beta-lactamase 1--Detected

TABLE 2: Enterobacter negative for KPC, positive for NDM-1

Blood cultures remained negative. Enterobacter was sensitive to Amikacin, Aztreonam, Gentamycin, Colistin, Tobramycin and Tigecycline.

Infectious disease specialist was consulted. Antibiotics were changed to IV Tigecycline and she was treated for one week. Colistin and aminoglycosides were not chosen as she has worsening creatinine during that time. The patient's wound significantly got better and she was discharged home. Later during an outpatient follow-up, her cellulitis got completely resolved but she had some residual venous stasis changes. 


\section{Discussion}

Carbapenem-resistant Enterobacteriaceae (CRE) infections are more recognized and reported worldwide because of the emergence and spread of strains producing carbapenemases. Carbapenemases are carbapenem hydrolyzing beta-lactamases that confer resistance to beta lactams as well as carbapenems. Emergence of bacteria with carbapenemases makes the battle of extreme drug resistance in gram negative bacilli much tougher [3]. There are different mechanisms involved in non-susceptibility to carbapenems among Enterobacteriaceae, including porin mutations that decrease carbapenem penetration with production of certain types of beta lactamases [4]. Carbapenem antibiotics have an important role in treating several gram-negative bacteria producing cephalosporinases and extended spectrum beta lactamases [5].

According to Ambler classification system, there are three classes of carbapenemases: Class A, B, and D beta-lactamases. Class A and D enzymes have a serine-based hydrolytic mechanism, and Class B enzymes are metallo beta lactamases with zinc in active site [6]. New Delhi metallo-beta-lactamase (NDM-1) is a type of B beta-lactamase gene that was first identified in Klebsiella pneumoniae in a Swedish patient treated in India in 2009 [7]. Earlier in the United States, Enterobacter isolates with NDM-1 gene were mostly identified in patients who received prior medical care in countries like India and Pakistan [8]. There were few cases reported with more than one type of carbapenemase producing strains from a single patient [6]. There were some cases reported in the USA where patients received prior care in middle eastern countries as well [9]. Initially the cases reported in the USA were from those patients who received prior medical care in other countries but later indigenous cases without previous travel have been reported [10].

Carbapenemase producing bacterial infections can vary from asymptomatic colonization to clinical infections like urinary tract infections, surgical wound infections, bacteremia, respiratory tract infections and abscesses [11-14]. Susceptibility testing should be done on all carbapenemase producing strains. NDM-1 positive strains have other concomitant resistance mechanisms which incur their resistance to other antimicrobials in addition to beta-lactams [15]. Optimal treatment is uncertain as antibiotic options are limited. Consultation with an infectious disease specialist should be made. Some of the regimens that were used in past to treat these infections are: ceftazidime-avibactam, Meropenem-Vaborbactam; ImipenemRelebactam, Polymyxins, Tigecycline, Eravacycline, and aztreonam [16-19].

Centers for Disease Control and Prevention (CDC) came up with guidelines to control and spread of CRE [20]. Enhanced hygiene, contact precautions (CP), pre-emptive isolation of high-risk patients, health care personnel education, patient and staff cohorting, antibiotic stewardship, inter facility communication are some of the core measures per CDC guidelines. Hospitalized patients should be placed on full $\mathrm{CP}$ for the length of hospitalization and also during future hospitalizations. There were no definitive recommendations on duration of contact precautions for future hospitalizations [20].

\section{Conclusions}

In the current antibiotic era with growing resistance to antibiotics, we should be judicious with antibiotic usage. Several carbapenemase gene carrying bacteria are being identified. Prompt infectious disease consultation should be made and multi-drug resistant infections should be treated with appropriate antibiotics in a timely manner to prevent further antibiotic resistance. At the same time, we should limit overuse and misuse of antibiotics and be aggressive with isolation and prevention of the spread of these multi-drug resistance bacteria like the ones with NDM-1 gene. There should be better laboratory methods for CRE screening and novel preventive interventions as well.

\section{Additional Information \\ Disclosures}

Human subjects: Consent was obtained by all participants in this study. Conflicts of interest: In compliance with the ICMJE uniform disclosure form, all authors declare the following: Payment/services info: All authors have declared that no financial support was received from any organization for the submitted work. Financial relationships: All authors have declared that they have no financial relationships at present or within the previous three years with any organizations that might have an interest in the submitted work. Other relationships: All authors have declared that there are no other relationships or activities that could appear to have influenced the submitted work.

\section{References}

1. Guh AY, Limbago BM, Kallen AJ: Epidemiology and prevention of carbapenem-resistant Enterobacteriaceae in the United States. Expert Rev Anti Infect Ther. 2014, 12:565-580. 10.1586/14787210.2014.902306

2. Centers for Disease Control and Prevention (CDC): Carbapenem-resistant Enterobacteriaceae containing New Delhi metallo-beta-lactamase in two patients - Rhode Island, March 2012. Morb Mortal Wkly Rep (MMWR). 2012, 61:446-448.

3. Jacoby GA, Munoz-Price LS: The new beta-lactamases. N Engl J Med. 2005, 352:380-391. 10.1056/NEJMra041359 
4. Paterson DL, Doi Y: A step closer to extreme drug resistance (XDR) in gram-negative bacilli . Clin Infect Dis. 2007, 45:1179-1181. 10.1086/522287

5. Gupta N, Limbago BM, Patel JB, Kallen AJ: Carbapenem-resistant Enterobacteriaceae: epidemiology and prevention. Clin Infect Dis. 2011, 53:60-67. 10.1093/cid/cir202

6. Queenan AM, Bush K: Carbapenemases: the versatile beta-lactamases . Clin Microbiol Rev. 2007, 20:440458. 10.1128/CMR.00001-07

7. Yong D, Toleman MA, Giske CG, Cho HS, Sundman K, Lee K, Walsh TR: Characterization of a new metallobeta-lactamase gene, bla(NDM-1), and a novel erythromycin esterase gene carried on a unique genetic structure in Klebsiella pneumoniae sequence type 14 from India. Antimicrob Agents Chemother. 2009, 53:5046-5054. 10.1128/AAC.00774-09

8. Doi Y, O'Hara JA, Lando JF, Querry AM, Townsend BM, Pasculle AW, Muto CA: Co-production of NDM-1 and OXA-232 by Klebsiella pneumoniae. Emerg Infect Dis. 2014, 20:163-165. 10.3201/eid2001.130904

9. Li J, Munoz-Price L, Spychala CN, DePascale D, Doi Y: New Delhi metallo- $\beta$-lactamase-1-producing Klebsiella pneumoniae, Florida, USA. Emerg Infect Dis. 2016, 22:744-746. 10.3201/eid2204.151176

10. Rasheed JK, Kitchel B, Zhu W, et al.: New Delhi metallo- $\beta$-lactamase-producing Enterobacteriaceae, United States. Emerg Infect Dis. 2013, 19:870-878. 10.3201/eid1906.121515

11. Hirakata Y, Izumikawa K, Yamaguchi T, et al.: Rapid detection and evaluation of clinical characteristics of emerging multiple-drug-resistant gram-negative rods carrying the metallo-beta-lactamase gene blaIMP. Antimicrob Agents Chemother. 1998, 42:2006.

12. Herbert S, Halvorsen DS, Leong T, et al.: Large outbreak of infection and colonization with gram-negative pathogens carrying the metallo-beta-lactamase gene blaIMP-4 at a 320-bed tertiary hospital in Australia. Infect Control Hosp Epidemiol. 2007, 28:98.

13. Leavitt A, Navon-Venezia S, Chmelnitsky I, Schwaber MJ, Carmeli Y: Emergence of KPC-2 and KPC-3 in carbapenem-resistant Klebsiella pneumoniae strains in an Israeli hospital. Antimicrob Agents Chemother. 2007, 51:3026. 10.1128/AAC.00299-07

14. Crespo MP, Woodford N, Sinclair A, et al.: Outbreak of carbapenem-resistant Pseudomonas aeruginosa producing VIM-8, a novel metallo-beta-lactamase, in a tertiary care center in Cali, Colombia. J Clin Microbiol. 2004, 42:5094. 10.1128/JCM.42.11.5094-5101.2004

15. Nordmann P, Poirel L, Walsh TR, Livermore DM: The emerging NDM carbapenemases. Trends Microbiol. 2011, 19:588-595. 10.1016/j.tim.2011.09.005

16. Wu G, Abraham T, Lee S: Ceftazidime-avibactam for treatment of carbapenem-resistant Enterobacteriaceae bacteremia. Clin Infect Dis. 2016, 63:1147-1148. 10.1093/cid/ciw491

17. Bratu S, Tolaney P, Karumudi U, Quale J, Mooty M, Nichani S, Landman D: Carbapenemase-producing Klebsiella pneumoniae in Brooklyn, NY: molecular epidemiology and in vitro activity of polymyxin B and other agents. J Antimicrob Chemother. 2005, 56:128-132. 10.1093/jac/dki175

18. Solomkin J, Evans D, Slepavicius A, et al.: Assessing the efficacy and safety of eravacycline vs ertapenem in complicated intra-abdominal infections in the investigating gram-negative infections treated with eravacycline (IGNITE 1) trial: a randomized clinical trial. JAMA Surg. 2017, 152:224-232. 10.1001/jamasurg.2016.4237

19. Bellais S, Mimoz O, Léotard S, Jacolot A, Petitjean O, Nordmann P: Efficacy of beta-lactams for treating experimentally induced pneumonia due to a carbapenem-hydrolyzing metallo-beta-lactamase-producing strain of Pseudomonas aeruginosa. Antimicrob Agents Chemother. 2002, 46:2032. 10.1128/AAC.46.6.20322034.2002

20. Centers for Disease Control and Prevention (CDC): Guidance for control of infections with carbapenemresistant or carbapenemase-producing Enterobacteriaceae in acute care facilities. MMWR Morb Mortal Wkly Rep. 2009, 20:256-260. 